\section{2}

Since 1998, a

decrease in the admission and length of hospital stay at the State Mental Hospital has been noted. At the same time, increases in the numbers of patients treated by family doctors as well as those referred have been recorded. and patients' relatives. This training facilitated the creation of a supportive environment for mental health problems.

Since 1998, a decrease in the admission and length of hospital stay at the State Mental H ospital has been noted. At the same time, increases in the numbers of patients treated by family doctors as well as those referred have been recorded.

The collaboration and involvement of all key partners is crucial for mental health promotion and prevention. The WHO has played an important role in the introduction of a mental health component in primary healthcare and the development of psychosocial rehabilitation.
References and further reading

Byambasuren, S. (1996) The Indicators of 60 Years' Prevalence of Mental Disorders in Mongolia. Ulaanbaatar.

Byambasuren, S. (2000) Community-Based Mental Health Service. Advanced Training Materials for Family Doctors, Vol. 3, p. 291. Ulaanbaatar.

Byambasuren, S., Erdenebayar, L., Tsetsegdary, G., et al (2003) Epidemiology of suicides among population in U laanbaatar city. M ongolian Medical Science, 3, 40-44.

Erdenebayar, L. \& Tsetsegdary, G. (2001) Mental health problems in Mongolia. In Public Health in the $\mathrm{New}$ Millennium, pp. 131-135. U laanbaatar.

Khishigsuren, Z., Gantsetseg, T. Byambasuren, S., et al (2004) Epidemiology of schizophrenia in Ulaanbaatar, Mongolia. Mongolian Medical Science, 4, 39-42.

World Health Organization (2001) Atlas: Country Profiles on Mental Health Resources. Geneva: WHO.

\title{
Mental health policy and programmes in Kenya
}

\author{
Frank G. Njenga ${ }^{1}$ and Pius A. Kigamwa ${ }^{2}$
}

${ }^{1}$ Chiromo Lane Medical Centre, University of Nairobi, Kenya, email fnjenga@africaonline.co.ke

${ }^{2}$ Department of Psychiatry, University of Nairobi

\section{Existing}

programmes are hampered by the shortage of commitment, personnel and funds. There is a tangible lack of commitment to mental health in Kenya, reflected in the fact that it receives less than $1 \%$ of the Ministry of Health's budget, which is itself less than 7\% of the national budget.
- ollowing a 10-year war of liberation (fought by the Mau Mau against the British), Kenya attained full independence from colonial rule in 1963. For 10 years the country enjoyed rapid economic growth (6-7\% per annum) but this slowed steadily to near stagnation in the 1990s. Poor governance, abuse of human rights, internal displacements of citizens, large numbers of refugees from neighbouring countries and the AIDS pandemic conspired to reduce Kenyans' life expectancy to 47 years (in the UK it is presently 77 years). Some $42 \%$ of the population now live below the poverty line, and $26 \%$ of Kenyans exist on less than US\$1 per day. The annual per capita income in Kenya is U $\$ 360$ (in the UK it is $\$ 24000$ ) (World Bank, 2002). AIDS currently has an estimated prevalence rate of $12 \%$. In large parts of rural Kenya many sexually active adults are unable to work, and elderly grandparents are left to look after orphaned children (some already infected with HIV), as they struggle to deal with their own grief for the loss of many of their own children. In December 2002 a new government was elected, which gives some grounds for optimism in an otherwise bleak situation.

\section{Mental health policy and resources}

Given the circumstances, it is unsurprising perhaps that mental healthcare was relegated to near oblivion; at present there is no mental health policy. Little or no thought was given to mental health as the country struggled with more life-threatening conditions, including diarrhoeal diseases, measles, malaria and tuberculosis. Commendable efforts are, however, in place to develop a policy with the assistance of the UK's Department for International D evelopment and the Institute of Psychiatry in London, which are now working on a collaborative project with Kenya, Tanzania and Zanzibar.

Existing programmes are hampered by the shortage of commitment, personnel and funds. There is a tangible lack of commitment to mental health in Kenya, reflected in the fact that it receives less than $1 \%$ of the Ministry of H ealth's budget, which is itself less than $7 \%$ of the national budget.

Kenya has only 47 psychiatrists for a population of 30 million, although there is the prospect of this number increasing, albeit slowly. More than half of them work in the major urban centres, while the majo rity of Kenyans live in the rural areas, which makes the relative shortage much worse.

Mathare Hospital started off in 1911 as an isolation unit for people with smallpox and is now a large, poorly resourced traditional mental hospital that houses approximately 750 mainly long-stay patients with psychosis, but it also serves as the forensic referral centre as well as an acute treatment centre. The buildings are in a state of disrepair and require major renovation. This is in marked contrast to the high morale of poorly paid staff, who work tirelessly without complaining and delivering, in their quiet way, a very high-quality service. A newly established drug rehabilitation unit is complemented by a well established occupational therapy department. 
The school of nursing, which used to train a high calibre of registered psychiatric nurses, closed some years ago. A disused British army military camp, $100 \mathrm{~km}$ from the capital, N airobi, houses several hundred chronically ill people, who have long since lost contact with their families. Some have been in hospital for more than 30 years.

\section{Services}

Kenya has eight provinces, each of which has a 30-bed psychiatric unit. These units are run by nurses and serve the catchment areas of the large provincial hospitals. Most units can prescribe basic drugs, generally limited to chlorpromazine, benzo diazepines, phenobarbitone and occasionally a tricyclic antidepressant. Although highly motivated, the staff, most of whom have worked in these units for many years, lack reading materials or indeed any contact with new knowledge in mental health practices. They are always keen to receive literature that could inform their practice. Most have no concept of mental health needs beyond psychosis and therefore do not diagnose or treat patients with depression or anxietyrelated disorders.

Few people with mental disorders attending primary care clinics receive a psychiatric diagnosis. In one study, $45 \%$ of people attending a health centre in $\mathrm{N}$ airobi had some form of psychiatric morbidity. All were misdiagnosed. Misdiagnosis is common because many people with a psychological disorder present with physical symptoms. This leads to frequent and unnecessary drug prescriptions and investigations.

\section{Training}

Although poorly resourced, Mathari Hospital is the main training centre for the $\mathrm{U}$ niversity of $\mathrm{N}$ airobi's medical and postgraduate students. A unique feature of the undergraduate training programme is the fact that psychiatry is a fully examinable subject taught to yearly classes of approximately 200 medical students. The department, which has 10 members of staff, also provides supervision and teaching to postgraduate students of paediatrics and internal medicine.

Kenya has had an active postgraduate training programme in psychiatry since the 1980 s, and most of the psychiatrists in Kenya have obtained their qualifications (Masters of Medicine) from this programme. Following a period of low enrolment, psychiatry has in the last few years become a popular subject of study and currently there are 20 students in the programme. Significantly, this programme has trained many psychiatrists now working in the region. A postgraduate diploma in psychotrauma is the most recent addition to the training.

A number of local universities have programmes both undergraduate and postgraduate - for the training of counselling psychologists, which is a very popular area of study, particularly following the 1998 bombing of the American Embassy in $\mathrm{N}$ airobi, which brought mental health issues to the fore ( $\mathrm{N}$ jenga et al, 2003, 2004). The tragedy had this one definite benefit to mental health.
A child psychiatry clinic was started by the principal author in 1981 at the Kenyatta $\mathrm{N}$ ational H ospital and now treats approximately 500 children per year. This unit serves as the main training venue for psychiatrists and paramedics in child psychiatry. There are, in addition, active if small programmes in private practice as well as active research in the areas of post-traumatic stress disorder and attention-deficit hyperactivity disorder. There are no formal training programmes in psychotherapy.

\section{Research}

Each postgraduate student of psychiatry at the U niversity of $\mathrm{N}$ airo bi is required to conduct original research as part of training. There is a great deal of (unpublished) research data available in the department in all fields of psychiatry. A number of recent publications from the department are, however, indicative of the resurgence of the vibrant academic culture which formerly characterised the department (0 thieno et al, 2001; Gatere et al, 2002; Maru et al, 2003). The department is a repository of much high-calibre research, spanning several decades, and any student of psychiatry in Africa would be well advised to consult the department before offering an authoritative opinion on African psychiatry.

0 ther Kenyan psychiatrists are active in research collaboration with international partners (Jenkins et al, 2002; Kiima et al, 2004). O ne area into which research is currently being undertaken is drug and alcohol misuse. In addition, an epidemiological survey of mental health disorders in a rural district of Kenya has recently been concluded; this was a unique project bringing together the Kenyan government, the Kenya Psychiatric Association and the Institute of Psychiatry in London (a World Health O rganization Collaborating Centre) (Jenkins et al, 2002).

\section{Meetings}

The main event for psychiatrists in East Africa is the annual meeting of Eastern Africa psychiatrists, which has taken place in different cities for the last 7 years; these meetings are alw ays well attended and the presentations of great scientific interest. The last, held in Arusha, Tanzania, was attended by the majority of Kenyan psychiatrists and attracted a large variety of presentations, including ones on drug misuse and AIDS, domestic violence, attention-deficit hyperactivity disorder, policy and service delivery. It attracted presentations from the entire region, as well as from the UK, the USA and South Africa. The organisers are always keen to involve people from others parts of the world, as they continue to struggle with the problem in small communities of 'intellectual inbreeding', whereby younger psychiatrists are exposed to the 'wisdom' and experience only of their seniors, which in turn is limited by their own experiences, idiosyncrasies and areas of interest. Exposure to other senior colleagues is often described as liberating and refreshing.
In one study, $45 \%$

of people

attending a health

centre in Nairobi

had some form of

psychiatric

morbidity. All

were mis-

diagnosed.

Misdiagnosis is

common because

many people with

a psychological

disorder present with physical

symptoms. This leads to frequent

and unnecessary drug prescriptions and

investigations.

Following a period of low

enrolment, psychiatry has in the last few years become a popular subject of study. 
Mental Health Act

There is much the North can learn from the South, in particular with regard to the utilisation of meagre resources.

The development of both the east and west has reached a dizzying pace, with huge investments in both

infrastructure and social services over the past two decades.

\section{Parameshvara Deva FRCPsych} email devaparameshvara@yahoo.com alaysia is a tropical country in the heart of South East Asia, at the crossroads of the ancient east-west sea trade routes. Although independent from British colonial rule only in 1957, it has a recorded history dating back to at least the first century $C E$, when the region was already the source of valuable mineral and forest produce that found markets in China, India and further west.

Malaysia has an area of over $330000 \mathrm{~km}^{2}$, divided between Peninsular Malaysia (formerly known as West Malaysia, south of Thailand) and Sabah and Sarawak (formerly known as East Malaysia, on the island of Borneo, on which are also Brunei and Kalimantan, part of Indonesia). Ethnically, the po pulation comprises 55\% $M$ alay and other indigenous people, 33\% Chinese and $9 \%$ Indians and other groups from South Asia. About 19 million of its 24 million inhabitants live in Peninsular Malaysia, while about 5 million live in the two states in Borneo, which have about three-fifths of the land area.
The current Mental Health Act (1989) provides for the establishment of a mental health board, which in theory regulates mental health services in the country. The Act also provides for voluntary and involuntary admission to those hospitals designated for this purpose under the Act. It also prohibits discrimination by insurance companies against persons with a mental illness. Efforts are currently being made to update the Act, in particular in the areas of safeguarding the human rights of people who have a mental illness. This, however, is low on the list of priorities in Kenya.

only a booming tourist destination but, like the nation's long-distance runners, proposes to capture, in the long run, researchers from the UK and other Euro-pean capitals. Such adventurers will be met with traditional African hospitality, which includes (these days) a mandatory hunting safari (photographic) to any of the game reserves. Sandy beaches on the coast and the snowcapped Mount Kenya come as extras. As we say in Kenya, 'To go is to see'.

\section{References}

Gatere, N., O thieno, C. J. \& Kathuku, D. M. (2002) Prevalence of tardive dyskinesia among psychiatric in-patients at Mathari Hospital, Nairobi. East African Medical Journal, 79 547-549.

\section{International collaboration}

The Royal College of Psychiatrists has a role to play in the promotion of mental health in Kenya, ranging from its participation in exchange programmes (to expose both members and the wider Kenyan public to the strengths and weaknesses of the systems in place in the two countries), as well as in its support of jo int research programmes. There is much the $\mathrm{N}$ orth can learn from the South, in particular with regard to the utilisation of meagre resources.

Traditional practitioners have skills that are yet to be researched, while drug trials can take place in (natural) settings in Kenya, where patients previously unexposed to medications are still to be found. Being a largely English-speaking population, and being only 8 hours from London by direct flight (21 a week), Kenya is not
Jenkins, R., Goldberg, D., Kiima, D., et al (2002) Classification in primary care: experience with current diagnostic systems. Psychopathology, 35, 127-131.

Kiima, D. M., N jenga, F. G., O konji, M. M., et al (2004) A Kenya mental health country profile. International Review of Psychiatry, 16, 48-53.

Maru, H. M., Kathuku, D. M. \& N detei, D. M. (2003) Substance use among children and young persons appearing in the $\mathrm{N}$ airobi juvenile court, Kenya. East African Medical Journal, 80, 598-602.

N jenga, F. G., N yamai, C. \& Kigamwa, P. (2003) Terrorist bombing at the US Embassy in Nairobi: the media response. East African Medical Journal, 80, 159-164.

N jenga, F. G., N yamai, C. N ., Kigamwa, P. A., et al (2004) Psychological reactions following the US Embassy bombing in $\mathrm{N}$ airobi. British Journal of Psychiatry, 185, 328-334.

0 thieno, C. J., O kech, V. C., O mondi, J. A., et al (2001) How Kenyan physicians treat psychotic disorders. East African Medical Journal, 78, 204-207.

World Bank (2002) World Development Report. Washington, DC: World Bank.

\section{Psychiatry and mental health in Malaysia}

Honorary Professor of Psychiatry, UPNG; Head of Department of Psychiatry, SSB Hospital, Kuala Belait, Brunei,

The two eastern states joined independent Malaya in 1963. They are less developed and have fewer social and health services. The widely distributed population centres in these two states are separated by numerous rivers, mountains and few roads, which poses major challenges to the provision of good medical and psychiatric services. On Peninsular Malaysia, however, the long established infrastructure of roads and communications has contributed to better development of health services. $\mathrm{N}$ onetheless, the develo pment of both the east and west has reached a dizzying pace, with huge investments in both infrastructure and social services over the past two decades.

\section{Development of health and mental health services in Malaysia}

There are few records of health services that existed in ancient times but resort to traditional, herbal and 